HNO 2021 $69: 544$

https://doi.org/10.1007/s00106-021-01068-3

Online publiziert: 10. Juni 2021

(c) Der/die Autor(en) 2021

J. Linke ${ }^{1}$ T. Eichhorn ${ }^{2} \cdot$ M. Kemper ${ }^{1} \cdot$ T. Zahnert ${ }^{1} \cdot$ M. Neudert ${ }^{1}$

'Klinik für Hals-, Nasen- und Ohrenheilkunde, Universitätsklinikum Carl Gustav Carus Dresden, Dresden, Deutschland

${ }^{2}$ Emeritus HNO-Klinik Carl-Thiem-Klinikum, Cottbus, Deutschland

\title{
Erratum zu: Die Weiterbildungssituation in der HNO-Heilkunde in Deutschland
}

\section{Erratum zu:}

HNO 2020

https://doi.org/10.1007/s00106-02000838-9

Der Artikel „Die Weiterbildungssituation in der HNO-Heilkunde in Deutschland“ von J. Linke, T. Eichhorn, M. Kemper, T. Zahnert, M. Neudert wurde ursprünglich am 4. März 2020 ohne „Open Access“ online auf der Internetplattform des Verlags publiziert. Die Autoren haben sich jedoch nachträglich für eine „Open Access"-Veröffentlichung entschieden. Das Urheberrecht des Artikels wurde deshalb am 6. Mai 2021 in (C) Der/die Autor(en) 2020 geändert.

\section{Korrespondenzadresse}

\section{Dr. med. J. Linke}

Klinik für Hals-, Nasen- und Ohrenheilkunde, Universitätsklinikum Carl Gustav Carus Dresden Fetscher Str. 74, 01307 Dresden, Deutschland jana.linke@uniklinikum-dresden.de

Funding. Open Access funding enabled and organized by Projekt DEAL.

Open Access. Dieser Artikel wird unter der Creative Commons Namensnennung 4.0 International Lizenz veröffentlicht, welche die Nutzung, Vervielfältigung, Bearbeitung, Verbreitung und Wiedergabe in jeglichem Medium und Format erlaubt, sofern Sie den/die ursprünglichen Autor(en) und die Quelle ordnungsgemäß nennen, einen Link zur Creative Commons Lizenz beifügen und angeben, ob Änderungen vorgenommen wurden.

Die in diesem Artikel enthaltenen Bilder und sonstiges Drittmaterial unterliegen ebenfalls der genannten Creative Commons Lizenz, sofern sich aus der Abbildungslegende nichts anderes ergibt. Sofern das betreffende Material nicht unter der genannten Creative Commons Lizenz steht und die betreffende Handlung nicht nach gesetzlichen Vorschriften erlaubt ist, ist für die oben aufgeführten Weiterverwendungen des Materials die Einwilligung des jeweiligen Rechteinhabers einzuholen.

Weitere Details zur Lizenz entnehmen Sie bitte der Lizenzinformation auf http://creativecommons.org/ licenses/by/4.0/deed.de.
Die Online-Version des Originalartikels ist unter https://doi.org/10.1007/s00106-020-00838-9 zu finden. 